\title{
Review of the Factors that Influence the Condition of Wax Deposition in Subsea Pipelines
}

\author{
Koh Junyi, Nurul Hasan

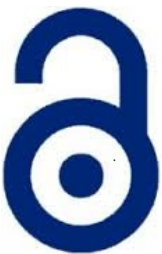 \\ Received: 10 October 2017 \\ Accepted: 20 February 2018 \\ Published: 30 March 2018 \\ Publisher: Deer Hill Publications \\ (c) 2018 The Author(s) \\ Creative Commons: CC BY 4.0
}

\begin{abstract}
When crude oil is transported via sub-sea pipeline, the temperature of the pipeline decreases at a deep depth which causes a difference in temperature with the crude oil inside. This causes the crude oil to dissipate its heat to the surrounding until thermal equilibrium is achieved. This is also known as the cloud point where wax begins to precipitate and solidifies at the walls of the pipeline which obstruct the flow of fluid. The main objective of this review is to quantify the factors that influence wax deposition such as temperature difference between the wall of the pipeline and the fluid flowing within, the flow rate of the fluid in the pipeline and residence time of the fluid in the pipeline. It is found the main factor that causes wax deposition in the pipeline is the difference in temperature between the petroleum pipeline and the fluid flowing within. Most Literature deduces that decreasing temperature difference results in lower wax content deposited on the wall of the pipeline. The wax content increases with rising flow rate. As for the residence time, the amount of deposited wax initially increases when residence time increases until it reaches a peak value and gradually decreases. Flow-loop system and cold finger apparatus were used in literature investigations to determine the trends above. Three new models are generated through a regression analysis based on the results from other authors. These new models form a relationship between temperature difference, flow rate, residence time and Reynolds number with wax deposition. These models have high values of R-square and adjusted R-square which demonstrate the reliability of these models.
\end{abstract}

Keywords. Wax deposition; influential factors for wax deposition; wax model development

\begin{tabular}{ll} 
SYMBOL/ABBREVIATION & \\
\hline WAT & Wax Appearance Temperature, ${ }^{\circ} \mathrm{C}$ \\
$T_{p}$ & Temperature of the walls of pipeline, ${ }^{\circ} \mathrm{C}$ \\
$T_{f}$ & Temperature of the fluid in the pipeline, ${ }^{\circ} \mathrm{C}$ \\
$\Delta T$ & Temperature difference between $\mathrm{T}_{\mathrm{p}}$ and $\mathrm{T}_{\mathrm{f}}{ }^{\circ} \mathrm{C}$ \\
WD & Wax deposition, weight in percentage (\%) \\
FR & Flow rate, ml/min \\
RS & Residence time, min \\
RN & Reynolds number (based on dia) \\
\hline
\end{tabular}

\section{INTRODUCTION}

The wax deposition has always been one of the most challenging and long-standing issues faced by petroleum industry when transporting crude oil via sub-sea pipelines. The temperature difference between the cold ambient temperature at the sub-sea level and the fluid is considered to be the main reason causing the formation of wax in the pipeline. For the wax to precipitate, the crude oil has to be at a temperature lower than WAT. This temperature is similar to the freezing point where a liquid or fluid begins to solidify[1, 2]. This causes a shrinkage in flow area of the pipeline deposited wax becomes thicker. When exposed to cold surroundings, the cooling of crude oil in the pipelines causes droplets to group together and solidifies, giving a cloudy appearance. The oil droplets eventually lose their flowability, causes blockage in the pipeline and can result in pressure rise Pipelines at an ocean floor experiences temperature of about $4^{\circ} \mathrm{C}$ and wax molecules begin to precipitate on the pipeline walls due to the cooling of crude

K. Junyi ${ }^{1}$ and N. Hasan² $\otimes$

'Department of Chemical Engineering, Faculty of Integrated Technologies, Universiti Brunei Darussalam, Brunei ${ }^{2}$ Petroleum and Chemical Engineering Programme, Faculty of Engineering, Universiti Teknologi Brunei, Brunei E-mail: nurulhasan@asme.org 
oil by the surrounding [3]. However, throughout the pipeline, the heat loss is inconsistent because there is a differential temperature gradient along the pipeline and this affects the rate of wax deposition [4]. To solve this critical issue, it is necessary to investigate and understand and quantify the factors that cause the problem for optimum crude productivity and flow assurance. The influencing factors that affect the behavior of wax deposition include the temperature gradient across the pipeline wall and the fluid within, flow rate and residence time.

Investigation of these factors involve the studies of two methods: The flow-loop system and cold finger apparatus. In flow-loop experiments, the fluids are circulated in a loop which it will pass through one or several measurements. Cold finger, on the other hand, is an equipment that bears a resemblance to a finger hence the name. It consists of a cold finger (a cylindrical metal heat exchanger), which is kept at a lower temperature and immersed in a higher temperature of the crude oil. Two separate water baths are used to control both temperatures (crude oil and cold finger) which can be varied for different thermal gradient $[5,6]$. It is simply a technique where a temperature controlled rod is submerged in heated oil, and a significant quantity of wax must precipitate before visual determination of deposition is visible. Therefore, this technique usually yields the lowest estimate of WAT and does not make a direct representation of wax deposition in oilfield pipelines [7]. Kelechukwu, Al Salim [8] conducted flow loop tests to investigate temperature difference, residence time and flow rate relations with wax deposition. The flow loop consists of several components: a stainless steel tank which acts as the reservoir, a twin pipe exchanger, a temperature controlled bath system and a hydrostatic pump whose purpose is to allow the mixture to move continuously. The reservoir tank has a radius of $180 \mathrm{~mm}$ and a height of $550 \mathrm{~mm}$ for holding $50 \mathrm{~L}$ reservoir. Included in the system is a centrifugal pump which is utilized to allow continuous flowing of the coolant (water), a bypass valve and thermocouples. The temperature was ranged from $40-55^{\circ} \mathrm{C}$, and the flow rate was varied from $100-500$ $\mathrm{ml} / \mathrm{min}$.

Charlton et al. 2017 [9] attempted to validate model of hydrate deposition used in OLGA. Molecular modeling is expensive, and an example is set of modeling Methane Hydrate by Chen et al. [10]. As understood the blockage risk in oil pipelines by hydrate [11] will cause problems in the years to come. Experiments on these phenomena are time-consuming and one of the bests approaches to perform solid-liquid-gas slug flow mechanistic model coupling hydrate dispersion formation with heat and mass transfer [12]. On the other hand, pore-scale formation of methane hydrate in the sand sediment using the phase-field model [13] is another way to capture the physics.

Mahto and Kumar [14] investigated temperature difference using flow loop setup that included $5 \mathrm{~L}$ hot bath filled with crude oil sample, which was pumped into test-tube of the flow line surrounded by a cooling jacket which is continuously circulating cooling water over the test tube. Their set-up is of smaller scale compared to experiments from Kelechukwu, Al Salim [8]. Deposition process initiates when circulating crude sample is cooled by the cooling jacket. The flow rate is determined by measuring the volume of crude oil collected in the measuring cylinder for a fixed time. After crude oil flows in the test tube for a different time interval (residence time), the flow is stopped, and diesel is circulated to wash the crude oil. The weight of the test tube is measured before, and after the experiment and the weight, difference indicates the amount of wax deposited during the flow. By studying and analyzing the results obtained from different authors, the objectives of interest is are enumerated in the followings:

- To quantify the temperature difference effect between the walls of the pipeline $\left(T_{p}\right)$ and the fluid $\left(T_{f}\right)$ on wax deposition.

- Review the relationship between flow rate of the fluid in pipeline and wax deposition.

- Study the impact of wax deposition due to the residence time of the fluid in the pipeline.

- To offer a general model of the factors influencing wax deposition.

- What about the flow types?

\section{RESULTS AND DISCUSSIONS}

According to research conducted by Kelechukwu et al.[8], it is found that the deposited wax in pipeline decreases with increasing temperature difference. The results are shown in Figure 1, Figure 2, Figure 3, and Figure 4. All four figures measure the similar parameter but differ in residence time. It can be seen that at any residence time, wax deposition decreases at the nearly consistent rate when there is an increase in differential temperature across the pipeline wall and the fluid. For example in Figure 1, at a low-temperature difference of $13^{\circ} \mathrm{C}$, the wax deposit weight is at approximately $0.33 \%$ while this value decreases to as low as $0.1 \%$ when temperature difference increases to $28^{\circ} \mathrm{C}$. Flow rate is maintained at $100 \mathrm{ml} / \mathrm{min}$. When the flow rate is varied, the trend of the graph remains mainly unchanged.

A similar experiment was conducted by Mahto and Kumar [14], and they obtained similar trend regarding the relationship between wax deposition and temperature difference. Their results are shown in Figure 5, Figure 6 and Figure 7 where the water bath in their model was kept constant at $23^{\circ} \mathrm{C}$ to allow accurate measurement for wax deposition. Wax deposition decreases with increasing differential temperature across the pipeline wall, and the fluid which is in complete understanding of previous work carried out by Cole and Jessen [15], Bott and Gudmundsson [16] and Haq [2]. However, these results were in disagreement with reports by Nazar, Dabir [17] and Jennings and Weispfennig [5] stating that increasing temperature difference will result in increasing amount of deposited wax. Impact on wax due to temperature difference conducted by Nazar et al. (2001) is illustrated in Figure 8 where the trend of the result is in contradiction to results from Kelechukwu et al. (2010) and Mahto and Kumar (2013) 


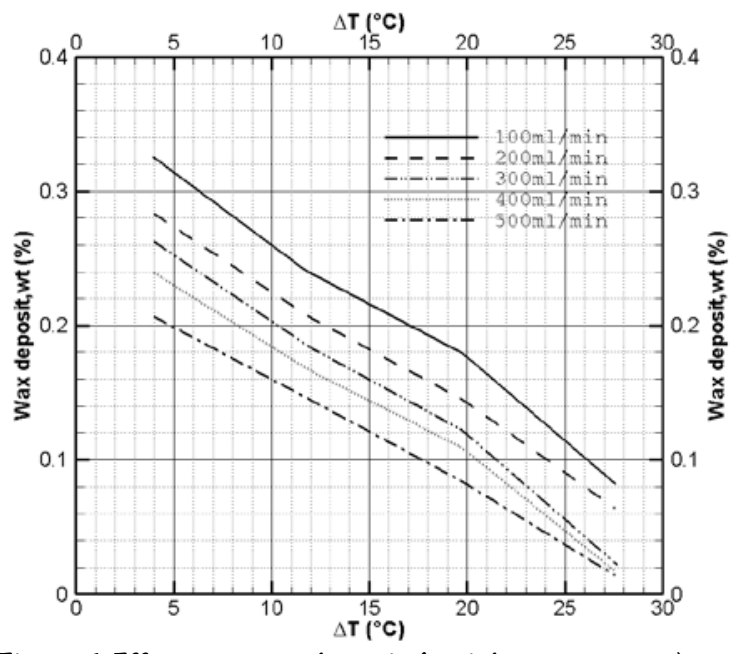

Figure 1 Effect on wax deposit (weight percentage) due to temperature differential at 3 min (kelechukwu et al., 2010)

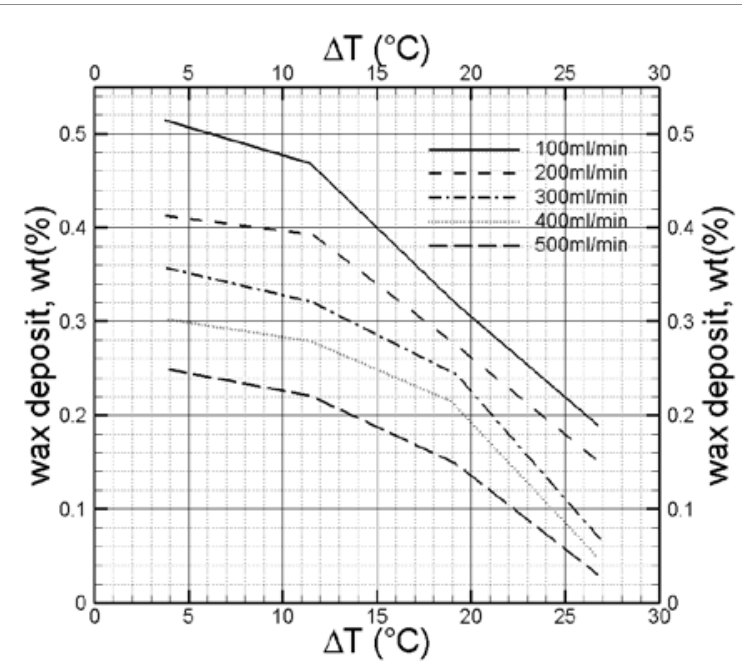

Figure 3 Effect on wax deposit (weight percentage) due to temperature differential at 9 min (kelechukwu et al., 2010)

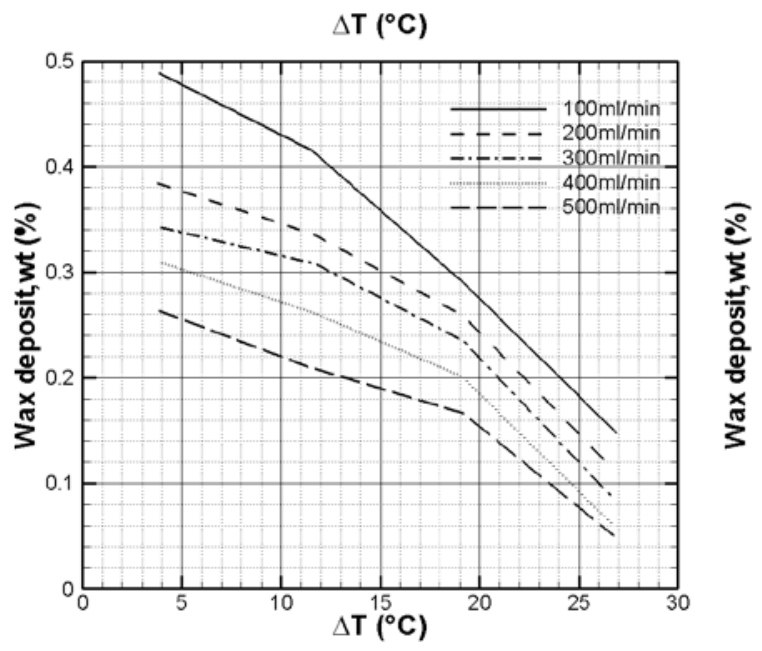

Figure 2 Effect on wax deposit (weight percentage) due to temperature differential at $6 \mathrm{~min}$ (kelechukwu et al., 2010)

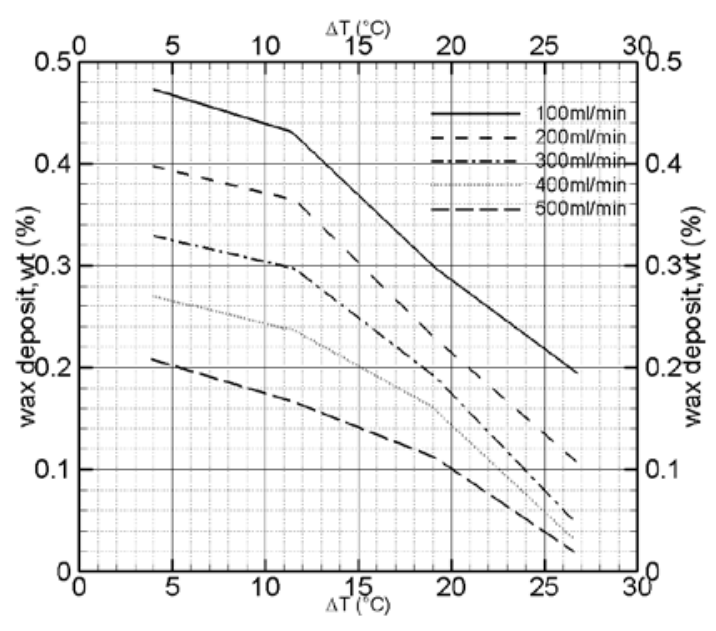

Figure 4 Effect on wax deposit (weight percentage) due to temperature differential at 12 min (kelechukwu et al., 2010)

Jennings and Weispfennig [5] experimented using coldfinger system and stated that their results could provide some insight into wax deposition process even though not as accurate as flow loop tests to represent wax deposition in real life subsea pipelines. Creek, Lund [18] conducted a test by keeping a constant temperature difference between the pipe walls and flowing oil of $8.3^{\circ} \mathrm{C}$ while decreasing the inlet temperature of the oil to as much as $25^{\circ} \mathrm{C}$ below the WAT. These tests were performed under laminar conditions. It was found that no deposition was observed when there was no temperature difference. Kelechukwu, Al Salim [8] investigated the impact on deposited wax at the pipeline wall due to flow rate on wax as shown in Figure 9, Figure 10, Figure 11 and Figure 12. At any temperature, it is observed that the deposited wax decreases with increasing flow rate. For instance, in Figure 8, the deposited wax percentage is at approximately $0.33 \%$ at $100 \mathrm{ml} / \mathrm{min}$ flow rate. As flow rate increases, the deposited wax gradually decreases until it attains $0.2 \%$ at $500 \mathrm{ml} / \mathrm{min}$. This result can be explained in terms of viscous drag which increases due to increasing velocity of the fluid. Viscous drag acts as a resistance force to the flow of the fluid hence will increase with increasing velocity according to the fluid dynamics. This force helps to cause the wax deposition layer to become thinner or even remove the deposited wax completely provided that the shear stress of the deposited wax is exceeded. As we can see from Figure 5, Figure 6 and Figure 7, Mahto and Kumar [14] obtained similar trend when experimenting on the effect of flow rate. At constant residence time and temperature differential, the wax deposit weight percentage decreased with increasing flow rate. Research on the impact of flow rate conducted by Creek, Lund [18] found that deposited wax increases in thickness when flow rate increases. This result applies for 
both laminar and turbulent flow. Brown, Niesen [19] suggest that deposited wax is harder when it is formed at the higher shear rate. These results are in agreement with results by Lund [20] and Venkatesan [21]. Since the fluid flows in the pipeline is of turbulent flow, it contributes greatly to the decrease in deposited wax with increasing flow rate. The increase in wax deposited however is due to a deposition process called diffusion in the laminar region. The decrease in a wax deposition with increasing flow rate while diffusion was responsible for the increase in a deposition with increasing flow rate in the laminar region [22]. Research also shows that when flow velocity exceeds $1.5 \mathrm{~ms}^{-1}$, wax deposition becomes very weak.

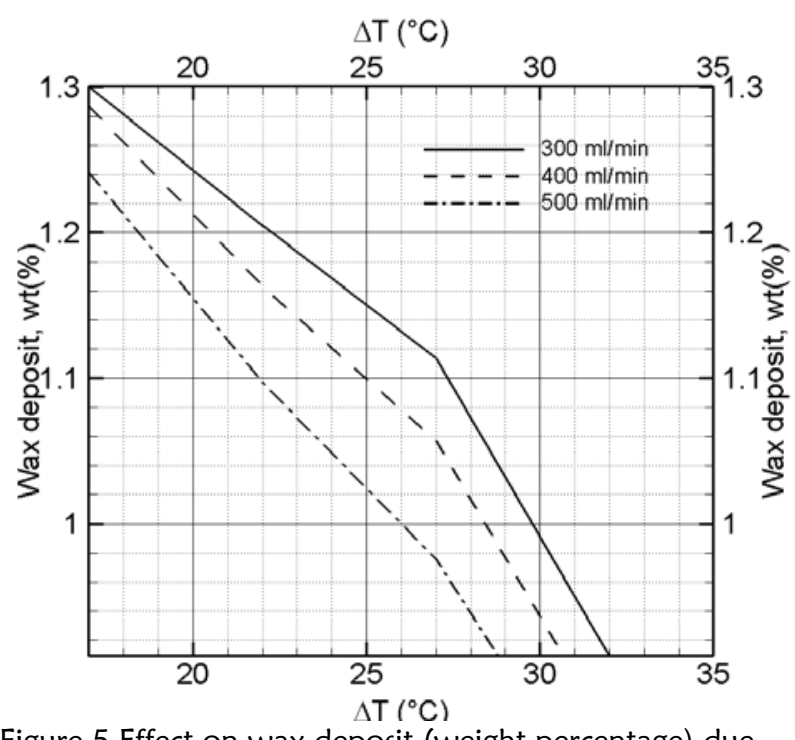

Figure 5 Effect on wax deposit (weight percentage) due to temperature differential at 60 min (Mahto and Kumar, 2013)

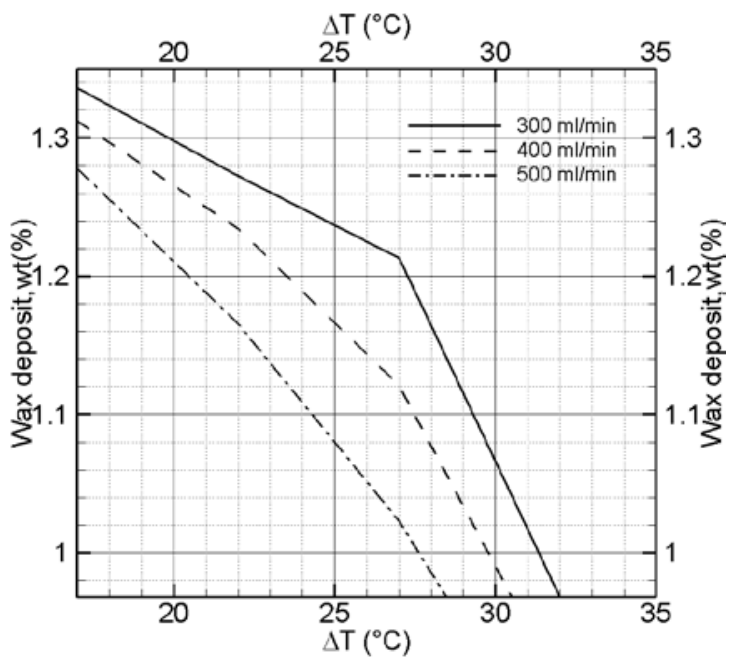

Figure 6 Effect on wax deposit (weight percentage) due to temperature differential at 180 min (Mahto and Kumar, 2013)

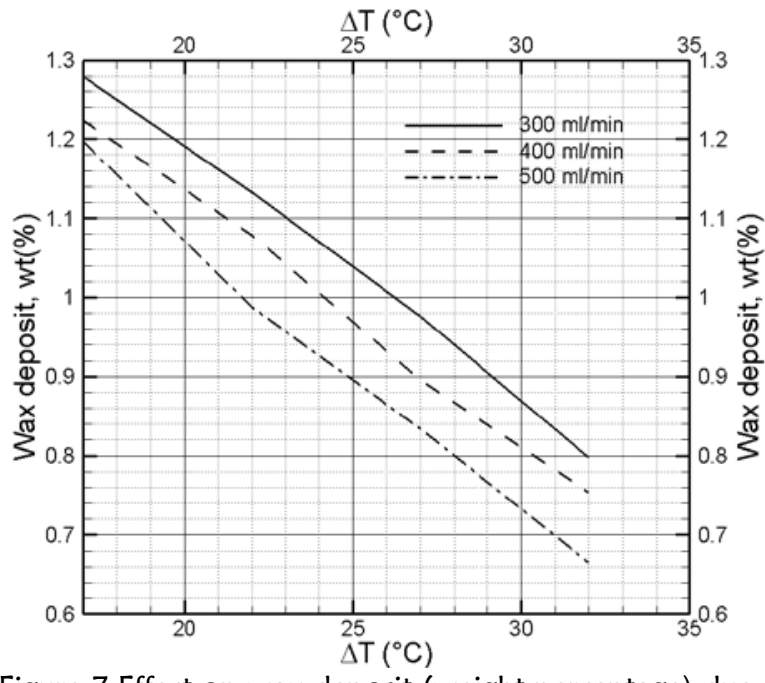

Figure 7 Effect on wax deposit (weight percentage) due to temperature differential at 300 min (Mahto and Kumar, 2013)

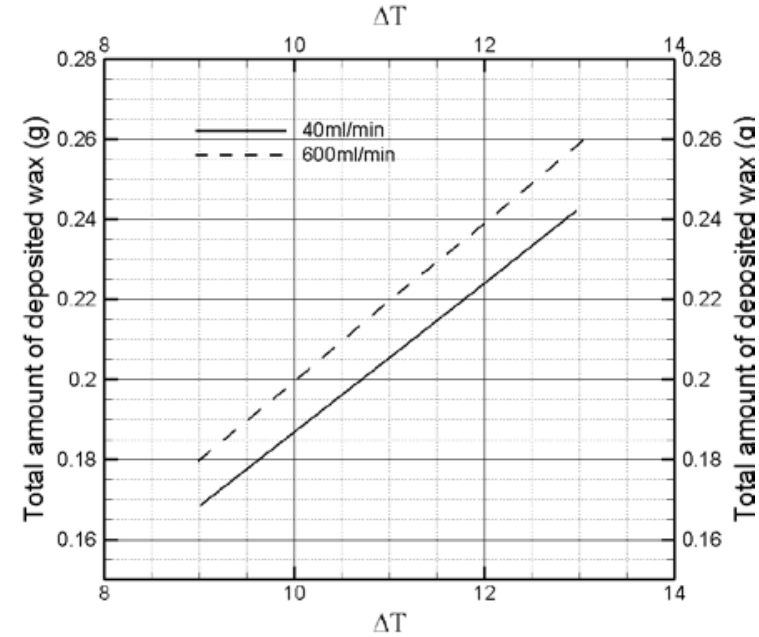

Figure 8 Effect on wax deposit due to temperature differential (Nazar et al., 2001)

Experimental results from Kelechukwu, Al Salim [8] on residence time are illustrated in Figure 13, Figure 14, Figure 15 and Figure 16, It was found that deposition of wax increases at a constant rate with increasing residence time but only up to certain point, where the deposition of wax increases at a slower rate. Lastly, the wax deposition decreases with increasing residence time. In Figure 13, it can be seen that wax deposit weight percentage increases linearly from $0.32 \%$ to $0.5 \%$ when the time is increased from 3 to $6 \mathrm{~min}$ at constant $13^{\circ} \mathrm{C}$. Then, the wax deposition slows down greatly and only increases by $0.1 \%$ for $9 \mathrm{~min}$. Then, the deposited wax gradually decreases until approximately $0.4 \%$ at $18 \mathrm{~min}$. These trends were found at other experimented flow rates of $200 \mathrm{ml} / \mathrm{min}, 300 \mathrm{ml} / \mathrm{min}, 400 \mathrm{ml} / \mathrm{min}$ 
and $500 \mathrm{ml} / \mathrm{min}$. The same author stated that residence time allows a higher rate of heat loss resulting in lower fluid temperature. This, in turn, causes the wax to precipitate and deposit at the wall of the pipeline. Since this experiment was conducted in a close-loop system, there is no continuous supply of fresh sample (fluid) therefore causing a depletion in a wax deposition at longer residence time. It was deduced that at a higher value of residence time, the amount of wax deposit drops because the layers of deposited wax provide thermal insulation [23].

To further strengthen this obtained result, Mahto and Kumar [14] also obtained similar trend even though their experiments are conducted at a higher time value. Their result is shown in Figure 17. These findings are in agreement with researchers by Cole and Jessen [15], Bott and Gudmundsson [16], Haq [2] and Towler and Rebbapragada [24]. However, it is important to note that this scenario cannot be applied in practical oilfield pipeline because the reservoir continuously supplies fresh crude oil. This result in shorter residence time for the fluid hence increased in wax deposition compared to experiments. Gooya, Gooya [25] conducted an experiment to investigate the relationship between $\Delta \mathrm{T}$, flow rate with wax deposition. The main difference his experimental setup differs from the other authors is Gooya et al. (2013) involves pipe length as the additional variable compared to the other authors. The results are shown in Figure 18 and Figure 19. It is found that wax thickness is at maximum during the first $200 \mathrm{~m}$ in the pipeline and a higher $\Delta T$ is recorded when the flow rate is lower during the first $3500 \mathrm{~m}$. For higher flow rate, $\Delta T$ is higher. This is due to deposition mechanisms which result in decreasing the stripping rate and concentration gradient. This causes a decrease $\Delta \mathrm{T}$ at pipe distance greater than $3500 \mathrm{~m}$.

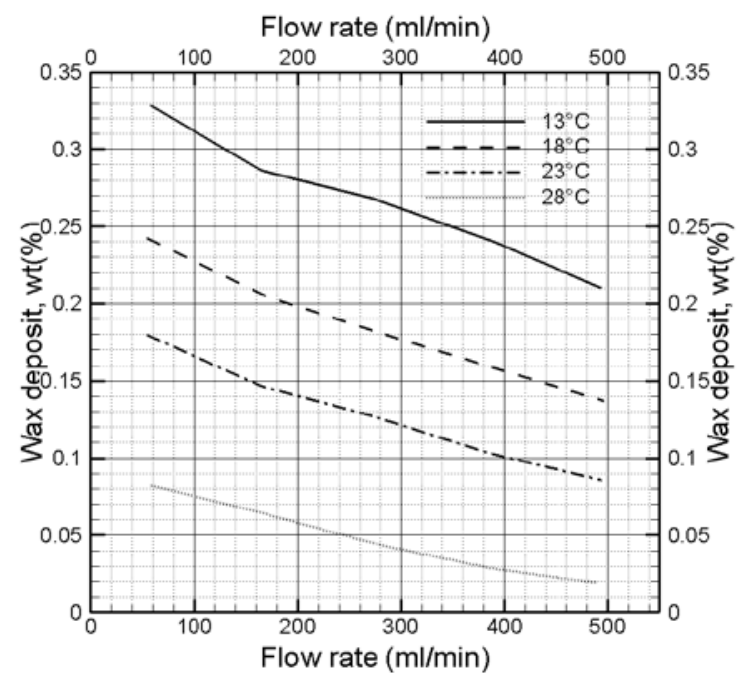

Figure 9 Effect of flow rate on deposited wax percentage at $3 \mathrm{~min}$ (Kelechukwu et al., 2010)

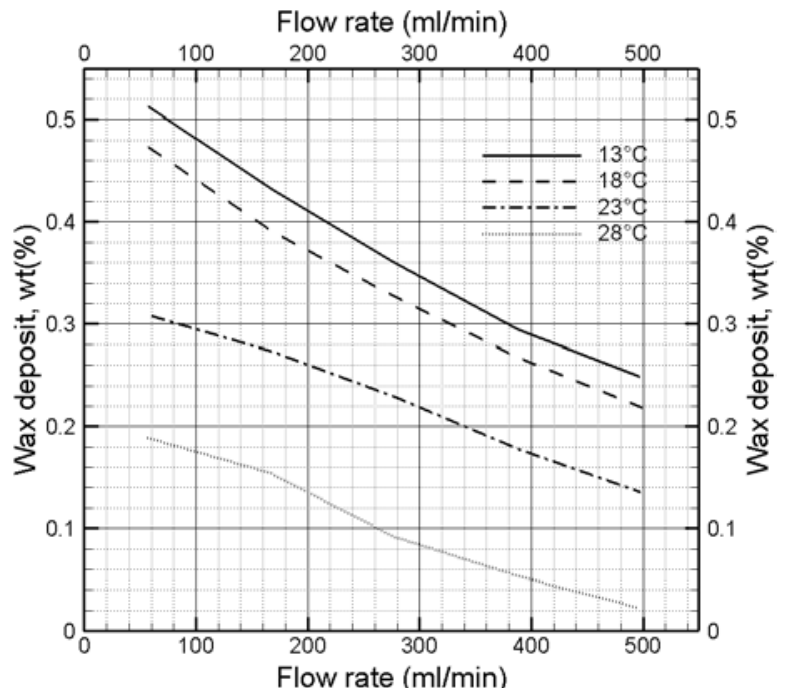

Figure 11 Effect of flow rate on deposited wax percentage at $9 \mathrm{~min}$ (Kelechukwu et al., 2010)

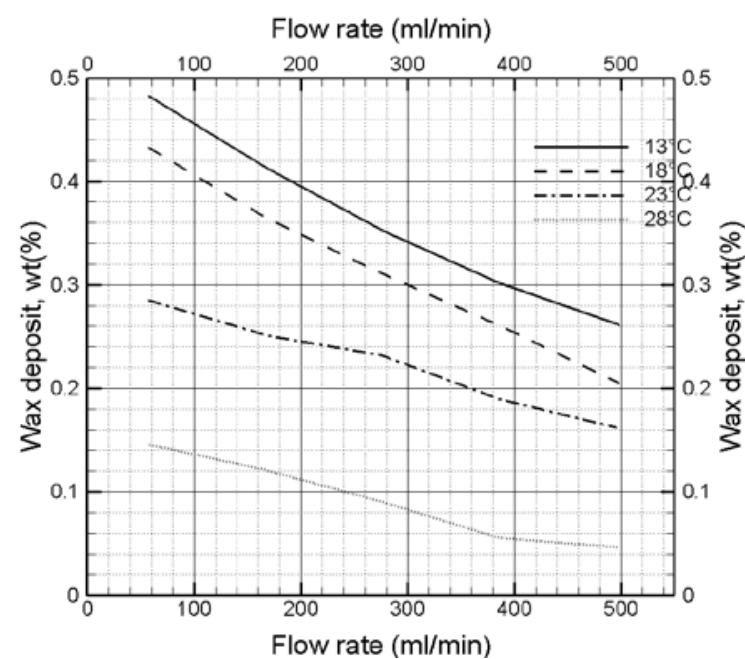

Figure 10 Effect of flow rate on deposited wax percentage at $6 \mathrm{~min}$ (Kelechukwu et al., 2010)

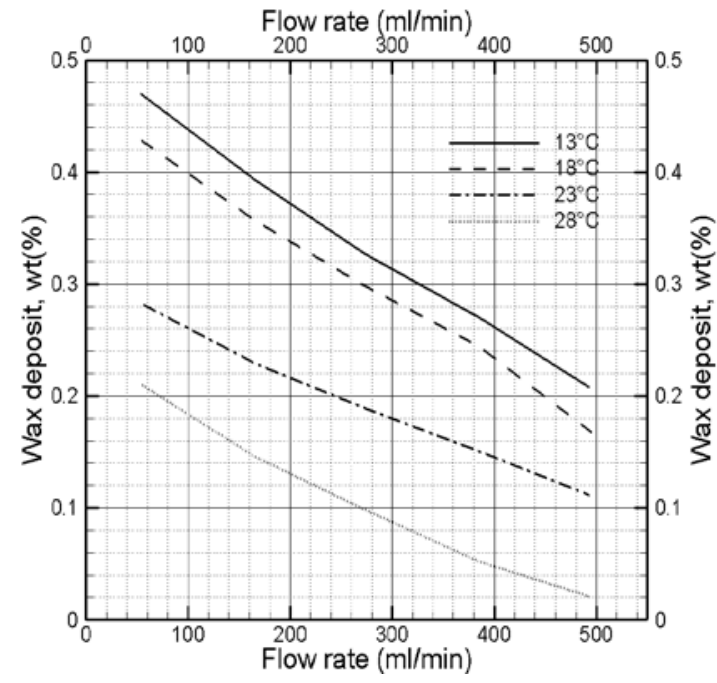

Figure 12 Effect of flow rate on deposited wax percentage at $12 \mathrm{~min}$ (Kelechukwu et al., 2010) 


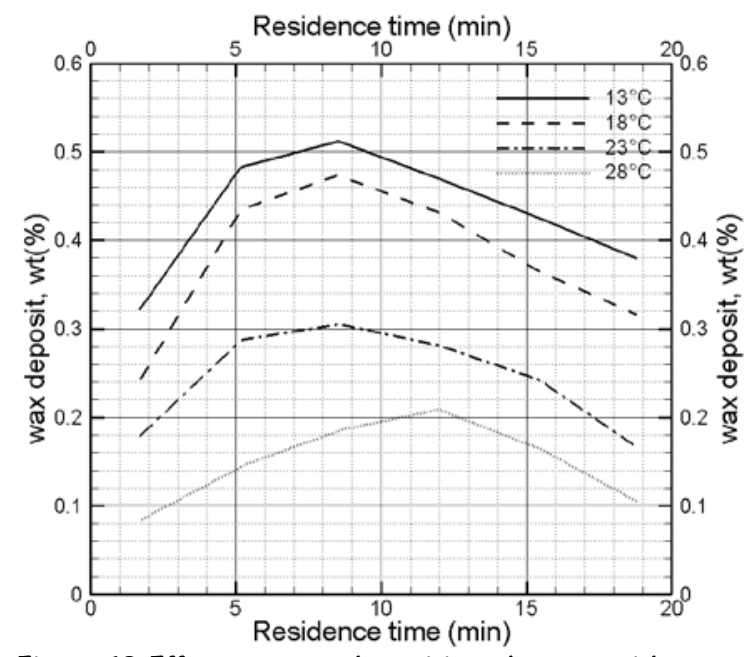

Figure 13 Effect on wax deposition due to residence time at $100 \mathrm{ml} / \mathrm{min}$ (Kelechukwu et al., 2010)

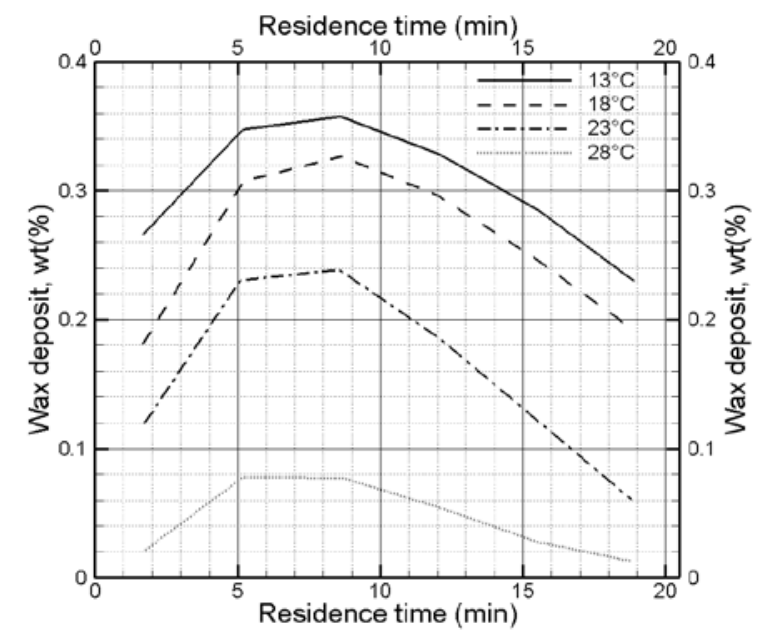

Figure 15 Effect on wax deposition due to residence time at $300 \mathrm{ml} / \mathrm{min}$ (Kelechukwu et al., 2010)

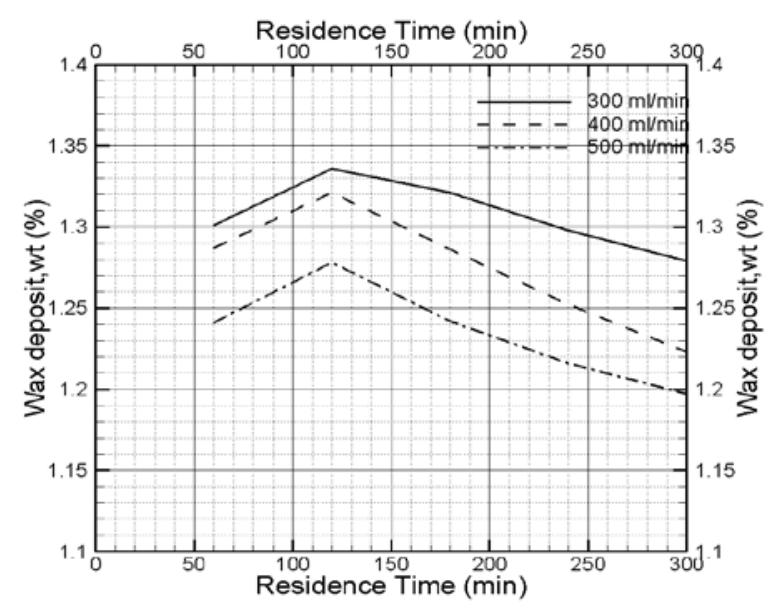

Figure 17 Effect on wax deposition due to residence time (Mahto and Kumar, 2013)

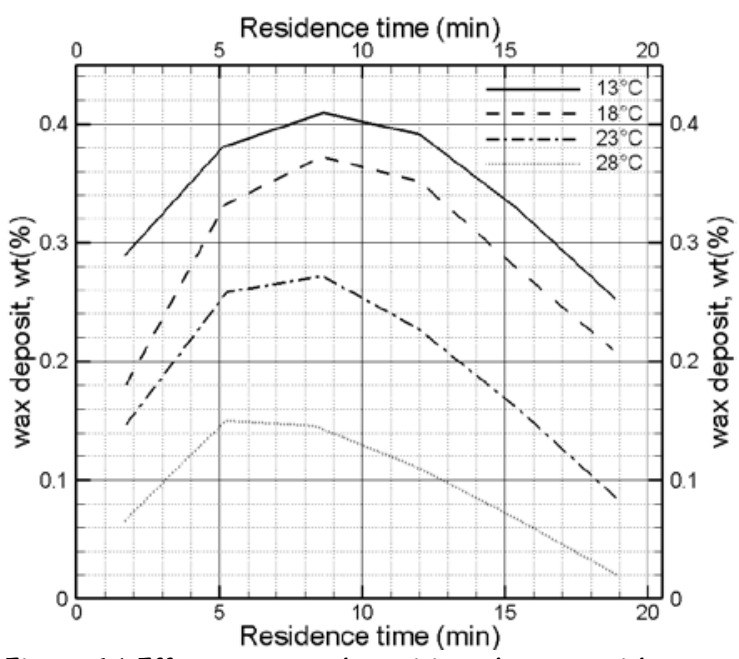

Figure 14 Effect on wax deposition due to residence time at $200 \mathrm{ml} / \mathrm{min}$ (Kelechukwu et al., 2010)

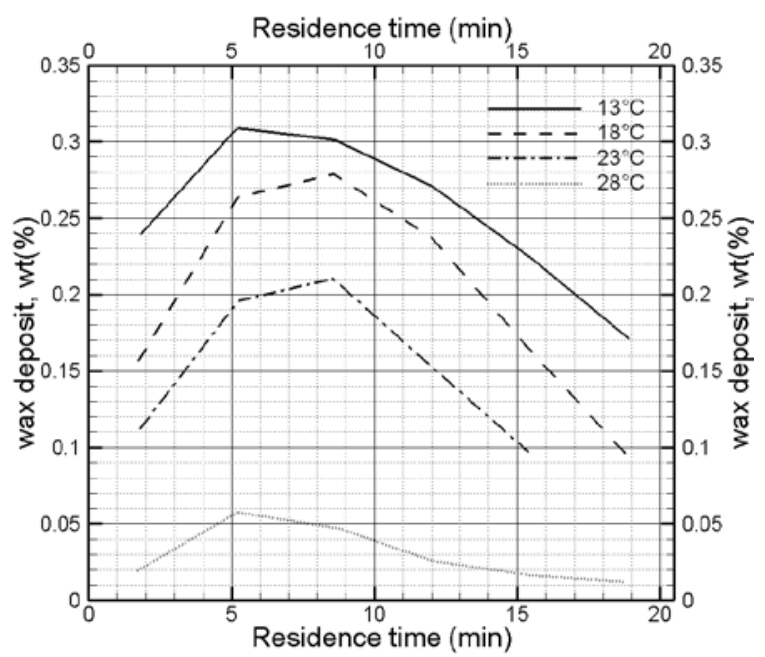

Figure 16 Effect on wax deposition due to residence time at $400 \mathrm{ml} / \mathrm{min}$ (Kelechukwu et al., 2010)

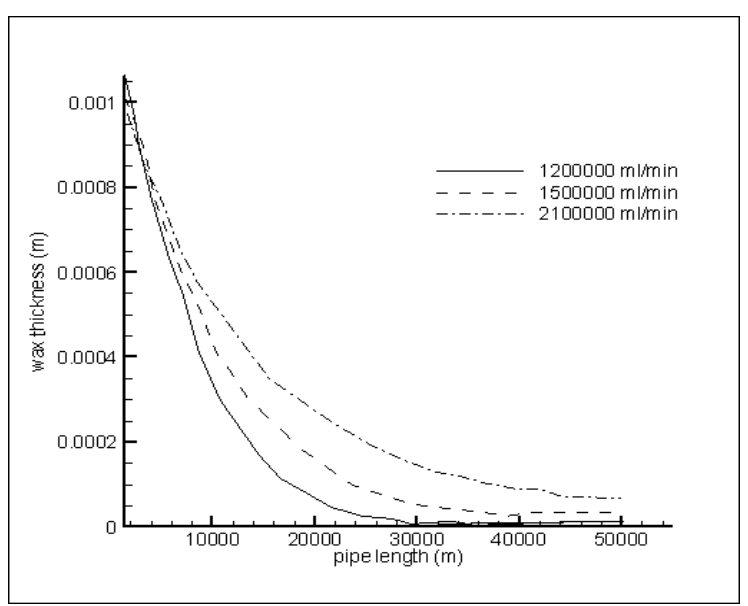

Figure 18 Effect of pipe length on wax thickness (Gooya et al., 1013) 
Using their results, regression analysis is attempted here to generate model relating all the variables $(\Delta T$, flow rate and residence time) with wax deposition. The results are shown in Figure 20, Figure 21, Figure 22 and new models have been developed as shown in the equation (1), equation (2) and equation (3) for wax deposit results based on Kelechukwu, Al Salim [8], Mahto and Kumar [14] and Gooya, Gooya [25] respectively. For this model, the values of R-square and adjusted R-square are 0.867 and 0.862 respectively. The standard error is just a low $4.6 \%$. The high value of adjusted $\mathrm{R}$ square and low standard error indicates that this model is a good fit. The coefficients for intercept, $\Delta \mathrm{T}$, flow rate and residence time are $0.46503,-0.01103,-0.00042$ and 0.00724 respectively. For this model developed, the R-square and adjusted R-square values are 0.968 and 0.963 respectively. These extremely high values back the validity of this model. The standard error is just a lowly $3.8 \%$. The coefficients for intercept, $\Delta \mathrm{T}$, flow rate and residence time are $2.34324,-0.02969,-0.00062$ and -0.00128 respectively. This developed model had high values of R-square and adjusted R-square which records 0.9737 and 0.9730 respectively. The standard error is at $0.07 \%$ which can be neglected because of its extremely low value. From all these values, it can be concluded that this model is the most fitting among all three models. This model records 0.00592 for intercept, $-4.1 \times 10^{-6}$ for $\Delta \mathrm{T}$, $2.15 \times 10^{-6}$ for flow rate, $-120 \times 10^{-6}$ for residence time and lastly -0.00306 for Reynolds number.

$$
\begin{aligned}
& W D=0.46503-0.01104 \Delta T-0.000042 F R+0.00724 R S \\
& W D=2.34324-0.02969 \Delta T-0.00062 F R+0.00128 R S \\
& W D=5.922-0.0041 \Delta T-0.00215 F R+0.00001 R S-3.06 R N
\end{aligned}
$$

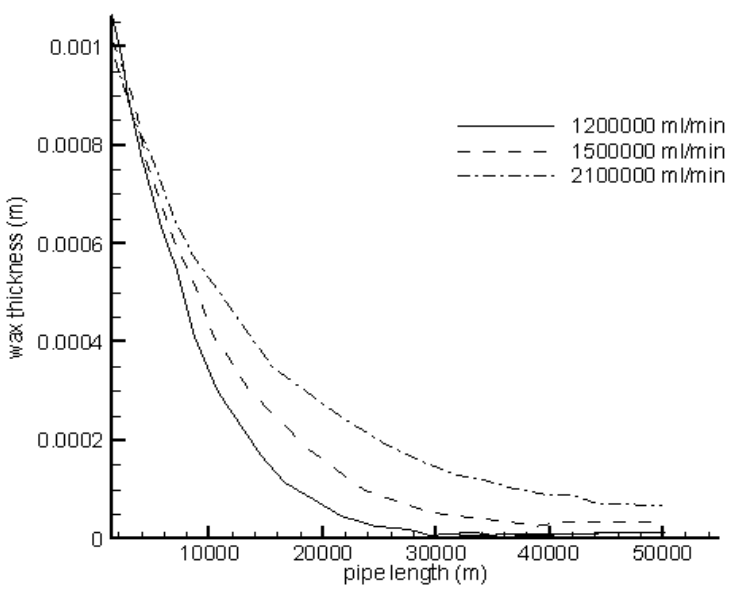

Figure 19 Relationship between $\Delta \mathrm{T}$ and pipe length (Gooya et al., 2013)

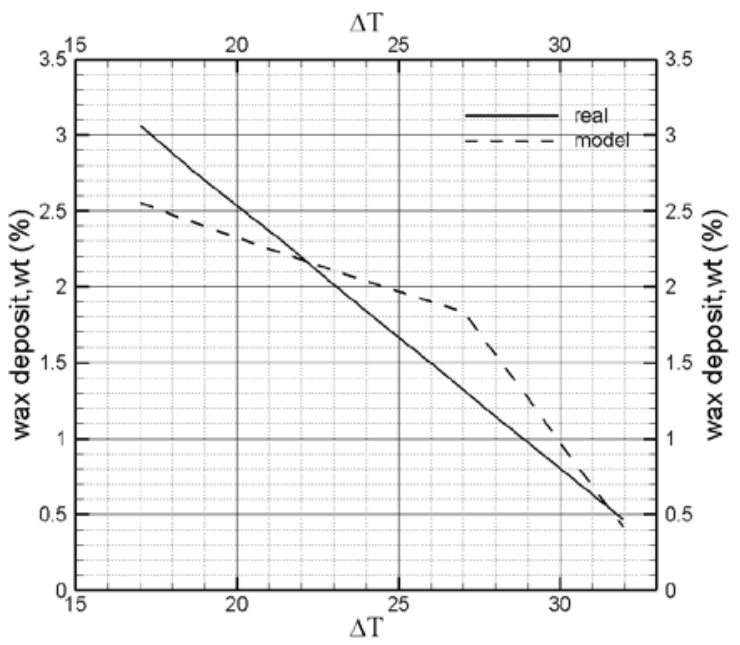

Figure 21 Comparison between real result and developed model for works by Mahto and Kumar (2013)

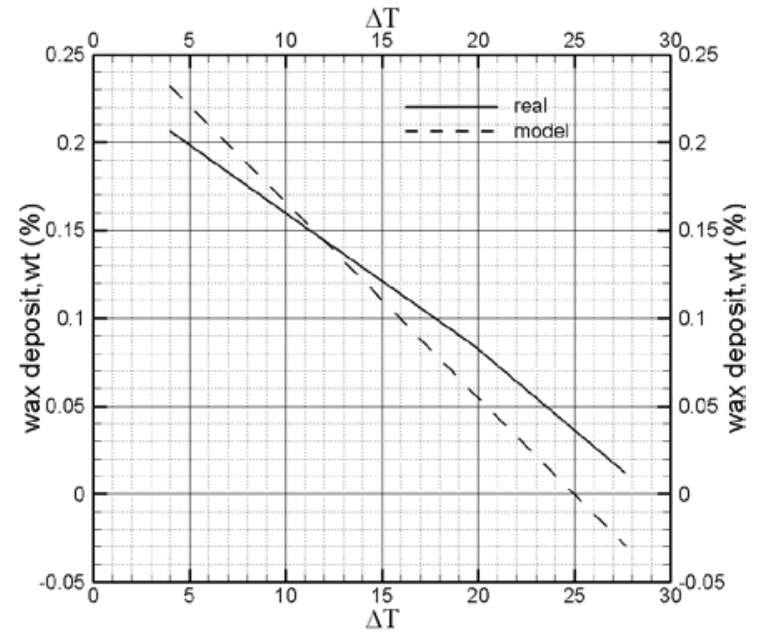

Figure 20 Comparison between real result and developed model for works by Kelechukwu et al. (2010)

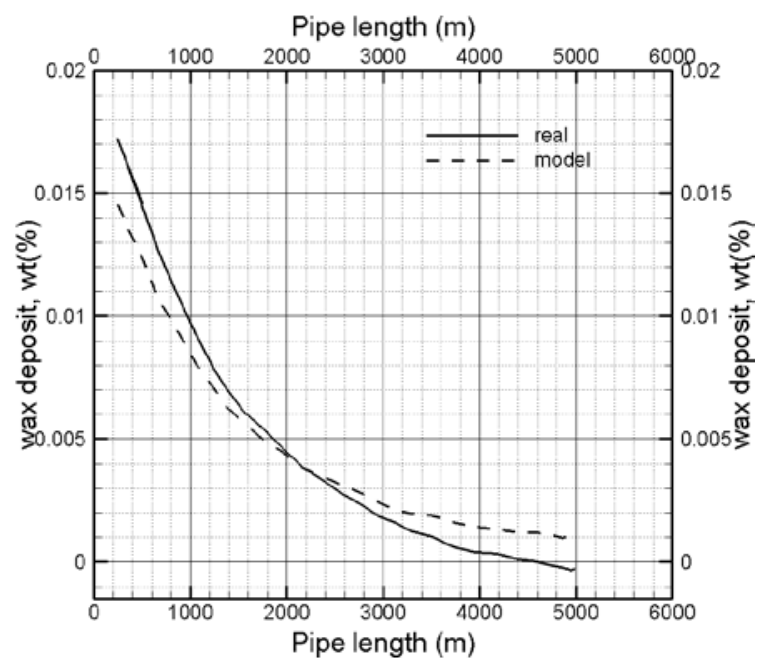

Figure 22 Comparison between real result and developed model for works by Gooya et al. (2013) 


\section{CONCLUSIONS}

Literature review on the impacts of the temperature differential across the pipeline wall and the fluid within, flow rate and residence time have on wax deposition is conducted in this paper. Flow-loop system and cold finger apparatus are used to simulate the paraffin wax deposition at wall pipeline which forms one of the core issues in the petroleum industry. The amount of wax deposited is plotted for every experiment conducted by different authors so that they can be easily analysed for every factor. It is concluded that temperature difference between the wall of pipeline and the fluid within represents the most important factor for wax deposition. There is still uncertainty whether a huge temperature differential leads to less wax deposition due to different results produced by different work. However, it is absolute that the amount of deposited wax decreases with the increased flow when conducted with both experiment setups. Also, the deposited wax increases with residence time but attain opposite result when the certain maximum time value is achieved. Regression analysis is applied to generate models relating all three influencing factors with wax deposition. R-square and adjusted R-square values for all models exceed $85 \%$ which backs the validity of the models. In total, three new models are generated. Despite that, further work is still needed in this scope to obtain more concrete results so that the more accurate influential rate of these factors are determined compared to real life flowing in subsea pipelines.

\section{REFERENCES}

1. Reistle Jr C. Methods of dealing with paraffin troubles encountered in producing crude oil. Bureau of Mines, Washington, USA, 1928.

2. Haq MA. Deposition of paraffin wax from its solution with hydrocarbons (USMS 10541). Soc. Petro Eng 1978.

3. Huang Z, Lee HS, Senra M, Scott Fogler H. A fundamental model of wax deposition in subsea oil pipelines. AIChE Journal 2011;57:2955-64.

4. Singh P, Venkatesan R, Fogler HS, Nagarajan N. Formation and aging of incipient thin film wax-oil gels. AIChE J 2000;46:1059-74.

5. Jennings DW, Weispfennig K. Effects of shear and temperature on wax deposition: Coldfinger investigation with a Gulf of Mexico crude oil. Energy \& Fuels 2005;19:1376-86.

6. Paso KG, Fogler HS. Bulk stabilization in wax deposition systems. Energy \& Fuels 2004;18:1005-13.

7. Lira-GC, Hammami A. Wax precipitation from petroleum fluids: A review. Dev Petro Science 2000;40:557-608.

8. Kelechukwu EM, Al Salim HSS, Yassin AAM. Influencing factors governing paraffin wax deposition during crude production. Int J Phy Sci 2010;5:2351-62.

9. Charlton TB, Di Lorenzo M, Zerpa LE, Koh CA, Johns ML, May EF, Aman ZM. Simulating Hydrate Growth and Transport Behavior in Gas-Dominant Flow. Energy \& Fuels 2017.

10. Ji H, Chen D, Zhao C, Wu G. Molecular Dynamics Simulation of Methane Hydrate Formation and Dissociation in the Clay Pores with Fatty Acids. J Phy Chem C 2018;122:1318-25.

11. Norris BWE, Johns ML, May EF, Aman ZM. Assessing hydrate blockage risk in oil pipelines: deploying a new transient simulation capability. Int Conf Multiphase Prod Technol; Cannes, France. 2017.

12. Bassani CL, Barbuto FAA, Sum AK, Morales REM. A three-phase solid-liquid-gas slug flow mechanistic model coupling hydrate dispersion formation with heat and mass transfer. Chem Eng. Sci 2018;178:222-37.

13. Fukumoto A, Kamada K, Sato T, Oyama H, Torii H, Kiyono F, Nagao J, Temma N, Narita H. Numerical simulation of pore-scale formation of methane hydrate in the sand sediment using the phase-field model. J Natural Gas Sci Eng 2018;50:269-81.

14. Mahto V, Kumar A. Effect of several parameters on wax deposition in the flow line due to Indian waxy crude oil. Int J Appl Eng Res Dev 2013;3:1-10.

15. Cole R, Jessen F. Paraffin deposition. Oil Gas J 1960;58:87-91.

16. Bott T, Gudmundsson J. Deposition of paraffin wax from kerosene in cooled heat exchanger tubes. Canadian J Chem Eng 1977; 55:381-5.

17. Nazar A, Dabir B, Islam M, editors. Measurement and modeling of wax deposition in crude oil pipelines. SPE Latin American and Caribbean Petroleum Engineering Conference; 2001: Society of Petroleum Engineers.

18. Creek J, Lund HJ, Brill JP, Volk M. Wax deposition in single phase flow. Fluid Phase Equilibria 1999;158:801-11.

19. Brown T, Niesen V, Erickson D, editors. Measurement and prediction of the kinetics of paraffin deposition. SPE Annual Tech Conf and Exhib; 1993: Soc Petro Engr.

20. Lund H. Investigation of Paraffin Deposition During Single Phase Flow in Pipelines. MSc. Thesis, Uni Tulsa, 1998.

21. Venkatesan R. The deposition and rheology of organic gels: University of Michigan.; 2004.

22. Agrawal K, Khan H, Surianarayanan M, Joshi G. Wax deposition of Bombay high crude oil under flowing conditions. Fuel 1990;69:794-6.

23. Hoteit H, Banki R, Firoozabadi A. Wax deposition and aging in flowlines from irreversible thermodynamics. Energy \& Fuels 2008;22:2693-706.

24. Towler BF, Rebbapragada S. Mitigation of paraffin wax deposition in cretaceous crude oils of Wyoming. J Petro Sci Eng 2004;45:11-9.

25. Gooya R, Gooya M, Dabir B. Effect of flow and physical parameters on the wax deposition of Middle East crude oil under subsea condition: Heat transfer viewpoint. Heat and Mass Transfer 2013;49:1205-16. 